\title{
Oxygen use and survival in patients with advanced cancer and low oxygen saturation in home care: a preliminary retrospective cohort study
}

\author{
Hiroshi Igarashi* ${ }^{*}$, Motoharu Fukushi and Naoki Nago
}

\begin{abstract}
Background: The role of oxygen therapy in end-of-life care for patients with advanced cancer is incompletely understood. We aimed to evaluate the association between oxygen use and survival in patients with advanced cancer and low oxygen saturation in home care.

Methods: We conducted a retrospective cohort study at a primary care practice in suburban Tokyo. Adult patients in home care with advanced cancer demonstrating first low oxygen saturation (less than 90\%) detected in home visits were consecutively included in the study. Cox proportional hazards regression was used to investigate the effect of oxygen use on overall survival and survival at home, adjusted for systolic blood pressure, decreased level of consciousness, dyspnea, oral intake, performance status, and cardiopulmonary comorbidity.

Results: Of 433 identified patients with advanced cancer, we enrolled 137 patients (oxygen use, $n=35$; no oxygen use, $n=102$ ) who developed low oxygen saturation. In multivariable analysis, the adjusted hazard ratio (HR) of oxygen use was 0.68 (95\% confidence interval 0.39-1.17) for death and $0.70(0.38-1.27)$ for death at home. In patients with dyspnea, the HR was 0.35 (0.13-0.89) for death and $0.33(0.11-0.96)$ for death at home; without dyspnea, it was $1.03(0.49-2.17)$ for death and $0.84(0.36-1.96)$ for death at home.

Conclusions: Oxygen use was not significantly associated with survival in patients with advanced cancer and low oxygen saturation, after adjusting for potential confounders. It may not be necessary to use oxygen for prolongation of survival in such patients, particularly in those without dyspnea.
\end{abstract}

Keywords: Cancer, Dyspnea, Hypoxia, Oxygen, Prognosis, Survival

\section{Background}

Low oxygen saturation is a common finding in patients with terminal cancer [1-3] and thus supplemental oxygen is frequently provided to patients with terminal cancer [4]. The use of oxygen is sometimes intended to alleviate dyspnea in patients with terminal cancer. However, it is not uncommon that the family hopes for prolonged survival, or healthcare providers recommend that oxygen be used for fear that not using it hastens death, especially in patients with low oxygen saturation. Studies have found that patients, caregivers, and healthcare providers perceive

*Correspondence: hiroshiiga@gmail.com

Musashi Kokubunji Park Clinic, 2-16-34-127 Nishimoto-machi, Kokubunji, Tokyo 185-0023, Japan oxygen as life-sustaining [5-7]. The potential influence of oxygen use on survival in patients with terminal cancer and low oxygen saturation may have important implications for end-of-life decision-making.

The effect of oxygen on dyspnea in patients who are terminally ill has not been established. Randomized controlled trials have shown that oxygen, compared with air, was not effective in alleviating dyspnea in these patients in the absence of severe hypoxemia; that is, partial pressure of oxygen in arterial blood $\left(\mathrm{PaO}_{2}\right)>55-60 \mathrm{mmHg}$ or oxygen saturation $>88-90 \%$ [8-11]. The use of oxygen for the relief of dyspnea in patients with advanced cancer who have low oxygen saturation is controversial [12-15]. 
Low oxygen saturation has been reported to be a risk factor for death in patients with advanced cancer [1-3, 16-18]. Randomized controlled trials have shown that long-term oxygen for patients with chronic obstructive pulmonary disease with severe hypoxemia resulted in reduced mortality [19, 20]. However, long-term oxygen provided no significant mortality benefit in patients with chronic obstructive pulmonary disease and resting oxygen saturation of $89-93 \%$, or exercise-induced moderate desaturation [21]. In contrast, no randomized controlled trial has been conducted on the effect of oxygen in patients who have advanced cancer and low oxygen saturation. Observational studies have found that oxygen use was a risk factor for death $[2,16,22,23]$. These results, however, may be confounded by low oxygen saturation before oxygen use. In addition, it is not clear that oxygen was used for patients with low oxygen saturation. Therefore, little is known about the association of oxygen use with survival in patients with advanced cancer who have low oxygen saturation.

Our study aimed to evaluate the association of oxygen use with survival in patients with advanced cancer demonstrating low oxygen saturation in home care, thereby informing end-of-life decision-making.

\section{Methods}

\section{Study design and population}

This was a cohort study conducted at a primary care practice in suburban Tokyo. Adult patients aged 20 years or older with locally advanced or metastatic cancer followed by a home medical care service provided by the practice were screened. Patients with first low oxygen saturation (peripheral arterial oxygen saturation measured by pulse oximetry < 90\%) detected in home visits between June 1, 2011 and November 30, 2018 were retrospectively identified by chart review and consecutively included in the study. Oxygen saturation was measured by the physicians who visited the patient's home or by the nurses who accompanied them, as part of the routine clinical practice for every patient under the home medical care service. All physicians and nurses measured oxygen saturation after ensuring that the patient was satisfactorily rested. Patients who had been on oxygen at the time of admission to the service and those for whom oxygen therapy was initiated before identification of decreased oxygen saturation were excluded from the study. The number of patients in the practice during the study period determined the sample size. Follow-up ended on November 30, 2018.

\section{Study variables}

All data on study variables were obtained by retrospective chart review. The exposure was the use of oxygen at home. The decision regarding whether to start supplemental oxygen was made following discussion between the patient, the family and the physician. The patient and family's wishes were respected. Whether to recommend supplemental oxygen was at the discretion of the attending physician, who did not always recommend oxygen to patients who developed low oxygen saturation. Oxygen was administered via a concentrator through a nasal cannula at $1-4 \mathrm{~L} / \mathrm{min}$ (mean, $1.9 \mathrm{~L} / \mathrm{min}$ ). Administration of oxygen by a mask was allowed in case of nasal irritation. Flow rate was determined at the discretion of the physician and adjusted to maintain an oxygen saturation of $90 \%$ or more. Oxygen was administered continuously at a steady flow rate unless the physician advised changing it. Intermittent use or increase of flow rate on exertion within a range of $1-4 \mathrm{~L} / \mathrm{min}$ was allowed at the patient's request.

Major potential confounders (decreased level of consciousness, dyspnea, oral intake, and performance status) were selected a priori based on previous literature regarding prognostic factors for survival in patients with advanced cancer [24-26]. Other factors considered to be potential confounders were age, sex, systolic blood pressure [23], heart rate [16, 22, 23, 25-27], oxygen saturation [16-18], edema [24, 28], cardiopulmonary comorbidity (heart failure or chronic lung disease), and lung cancer as the primary tumor [25]. We considered demographics and factors that might affect survival in patients with advanced cancer based on previous literature or on clinical basis, to be potential confounders. Respiratory rate was excluded from the potential confounders considered because of large numbers of missing data. All of the potential confounders were assessed at the time of development of low oxygen saturation. We used Doctor Bayes (Macros Japan, Tokyo, Japan), a Bayes theorem-based clinical decision support system that can be used in conjunction with electronic health records for recording patients' symptoms [29]. This system can record all patients' reason-forencounter and diagnosis codes. At each home visit, each patient's symptoms were entered into Doctor Bayes, according to the International Classification of Primary Care, second edition (ICPC-2) codes, by one of the family physicians in the practice [30]. When patients were unable to self-report their symptoms, reports from their family were included in patients' symptoms. Decreased level of consciousness, dyspnea, and edema were considered present when the ICPC-2 codes A07 (coma), R02 (shortness of breath/dyspnea), and K07 (swollen ankles/ edema), respectively, were recorded in the patient's medical record. Patients with confusion, drowsiness, or delirium were also included, together with comatose patients, in the decreased level of consciousness cohort. When the relevant ICPC-2 code was not recorded but there was a clear description of the symptoms in the patient's 
medical record, that symptom was considered present. Oral intake and performance status were determined according to the description in the patient's medical record. Oral intake was categorized into normal (able to eat as much as the patient ate when he or she was in good health), reduced (able to eat, but less than the amount the patient ate when he or she was in good health), or impossible (not able to eat at all). Performance status was recorded using the Eastern Cooperative Oncology Group Performance Status (ECOG) [31]. Cardiopulmonary comorbidity was considered present in patients with heart failure or chronic lung disease that possibly caused low oxygen saturation. Dyspnea was prespecified as a potential effect modifier.

Patients were followed with home visits, typically once or twice plus as needed in a week. Oxygen saturation at baseline, the highest, and the lowest reading during the follow-up at home were recorded according to the use of oxygen.

The main outcome measures were overall survival and survival at home. Overall survival was defined as the time from the development of low oxygen saturation until death, including instances after the end of followup at home. The date of death after the end of follow-up at home was ascertained by the report from the hospital, including the palliative care unit, to which the patient was admitted or referred. When it was not available, overall survival was censored at the end of follow-up at home. Survival at home was defined as the time from the development of low oxygen saturation until death at home. Patients were censored at the end of follow-up at home (e.g., hospital admission) for survival at home. We selected survival at home as one of the main outcome measures because oxygen use after the end of follow-up at home could not be ascertained and could potentially influence overall survival.

\section{Statistical analysis}

Medians with corresponding interquartile range (IQR) were calculated for overall survival and survival at home using the Kaplan-Meier survival function. The statistical significance of estimates from Kaplan-Meier survival curves for overall survival and survival at home were tested using the log-rank test. The statistical significance of the difference in the proportion of patients who died was assessed using Fisher's exact test, as was the proportion of patients who died at home.

Cox proportional hazards regression was used to calculate hazard ratios (HR) and 95\% confidence intervals (CIs) for overall survival and survival at home, adjusted for potential confounders. We incorporated a priori variables and variables remained statistically significant at a level of $p<0.10$ in the univariate analysis, into the final multivariate model.
Missing data were imputed with multiple imputation by chained equations (MICE). We assumed data were missing at random. We performed imputation with linear regression for systolic blood pressure and heart rate; predictive mean matching ( $\mathrm{k}$-nearest neighbors, $\mathrm{k}=3$ ) for oxygen saturation; logistic regression for decreased level of consciousness and edema; and ordered logistic regression for oral intake and performance status. Twenty imputed data sets were generated, with the results combined using Rubin's Rules.

Potential effect modification of oxygen use by dyspnea was investigated by stratification. Complete-case analysis was also performed.

A $p$-value $<0.05$ was considered statistically significant. All statistical analyses were performed using Stata Statistical Software: Release 14 (StataCorp LP, College Station, TX, USA).

\section{Results}

Of 433 adult patients with advanced cancer, a total of 137 patients (oxygen use, $n=35$; no oxygen use, $n=102$ ) who developed low oxygen saturation were consecutively included in the study (Fig. 1).

The baseline characteristics of the patients included in the study according to oxygen use are presented in Table 1 . The median age of the patients was 77 years; $62 \%$ were men, and $85 \%$ were of ECOG Performance Status 3 or 4 .

Outcome data of the patients included in the study according to oxygen use are presented in Table 2. Oxygen saturation during follow-up at home was higher in patients who used oxygen compared with those who did not. During a median of 8 days (IQR 2-23) (oxygen use, 15 days [IQR 6-34]; no oxygen use, 5 days [IQR 1-19]) of the entire follow-up, 129 patients (94\%) died. During a median of 6 days (IQR 2-19) (oxygen use, 14 days [IQR 5-32]; no oxygen use, 4 days (IQR 1-32]) of follow-up at home, 100 patients (73\%) died at home. There was no significant difference in the proportion of patients who died between the two groups $(p=1.0)$, nor in the proportion of those who died at home $(p=0.28)$. The median overall survival was 7 days (IQR 2-23) (oxygen use, 15 days [IQR 6-35]; no oxygen use, 5 days [IQR $1-19$ ]; $p=0.008$ ) (Fig. 2). The median survival at home was 10 days (IQR 2-31) (oxygen use, 19 days [IQR 7-46]; no oxygen use, 6 days [IQR 2-29]; $p=0.017$ ).

Univariate analysis of oxygen use and potential confounders for survival are presented in Table 3. The unadjusted HR of oxygen use was 0.59 (95\% CI $0.39-0.88$; $p=0.011)$ for death and 0.58 (95\% CI 0.36-0.92; $p=$ $0.021)$ for death at home.

Multivariate analysis of oxygen use and potential confounders for survival are presented in Table 4. We incorporated a priori variables and variables remained 
433 patients with advanced cancer were assessed for eligibility

295 were excluded:

226 did not develop low oxygen saturation

61 were on oxygen at the time of admission to home care

8 started oxygen before lowering of oxygen saturation

138 developed low oxygen saturation

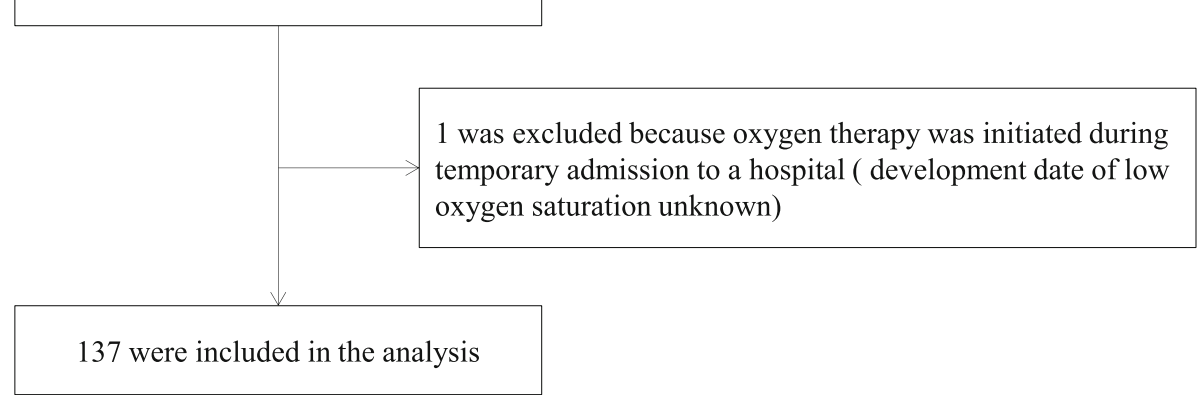

Fig. 1 Selection of study participants

statistically significant at a level of $p<0.10$ in the univariate analysis, into the final multivariate model. Consequently, the multivariate model was adjusted for systolic blood pressure, decreased level of consciousness, dyspnea, oral intake, performance status, and cardiopulmonary comorbidity. The adjusted HR of oxygen use was 0.68 (95\% CI $0.39-1.17 ; p=0.16$ ) for death and 0.70 (95\% CI $0.38-1.27 ; p=0.24$ ) for death at home.

Effect modification of oxygen use by dyspnea is summarized in Table 5. The adjusted HR of oxygen use was 0.35 (95\% CI $0.13-0.89 ; p=0.027$ ) for death and 0.33 (95\% CI $0.11-0.96 ; p=0.041)$ for death at home in patients with dyspnea. In contrast, the adjusted HR of oxygen use was 1.03 (95\% CI $0.49-2.17 ; p=0.94)$ for death and $0.84(95 \%$ CI $0.36-1.96 ; p=0.68)$ for death at home in patients without dyspnea.

Complete-case analysis yielded similar results as those in the analysis using multiple imputation (data not shown).

\section{Discussion}

In this retrospective cohort study of patients with advanced cancer and low oxygen saturation in home care, oxygen use was not significantly associated with survival, after adjusting for known prognostic factors and cardiopulmonary comorbidity. Oxygen use was associated with longer survival in patients with dyspnea, whereas no significant association was found in patients without dyspnea.
To our knowledge, this study is the first to investigate the association of oxygen use with survival in patients with advanced cancer who have low oxygen saturation. As expected, in univariate analysis, survival was longer in patients who used oxygen compared with those who did not. In multivariate analysis, however, there was no significant difference in survival between the two groups, after adjusting for potential confounders. This study suggests that, while oxygen tended to be foregone in patients with serious illness who were expected to die within several days, oxygen use per se had no significant effect on survival. In this study, more patients who did not use oxygen had risk factors for shorter survival (i.e., decreased level of consciousness, decreased oral intake, and lower performance status) at baseline, compared with those who used oxygen. This finding is consistent with previous studies, in which a diagnosis of "terminal" or "dying" was associated with decisions about the limitation of treatment in patients with cancer [32, 33]. The result of this study seems plausible, both clinically and biologically, for several reasons. First, the patient population in this study had a relatively short survival, with a median overall survival of 7 days. Patients with such severe illness may have had a short duration of survival, whether they used oxygen or not. Our findings parallel the result of a randomized controlled trial, in which there was no significant difference in survival between the parenteral hydration and placebo groups in patients with advanced cancer and dehydration [34]. Second, a 
Table 1 Baseline characteristics of patients with advanced cancer according to oxygen use

\begin{tabular}{|c|c|c|c|}
\hline & $\begin{array}{l}\text { Oxygen use } \\
(n=35)\end{array}$ & $\begin{array}{l}\text { No oxygen use } \\
(n=102)\end{array}$ & $\begin{array}{l}\text { Total } \\
(n=137)\end{array}$ \\
\hline Age, median (IQR), years & $74(69-80)$ & $78(69-83)$ & $77(69-82)$ \\
\hline Sex, male, no. (\%) & $18(51)$ & $67(66)$ & $85(62)$ \\
\hline Systolic blood pressure, mean (SD), mmHg & $117.0(21.9)$ & $104.1(22.8)$ & $107.3(23.1)$ \\
\hline Unknown, no. (\%) & $2(5.7)$ & $1(1.0)$ & $3(2.2)$ \\
\hline Heart rate, mean (SD), beats/min & $102.7(17.9)$ & $94.1(17.8)$ & $96.3(18.2)$ \\
\hline Unknown, no. (\%) & $1(2.9)$ & $3(2.9)$ & $4(2.9)$ \\
\hline Respiratory rate, median (IQR), breaths/min & $23(18-33)$ & $20(16-27)$ & $20(16-30)$ \\
\hline Unknown, no. (\%) & $13(37)$ & $45(44)$ & $58(42)$ \\
\hline Oxygen saturation, median (IQR), \% & $85(82-87)$ & $86(83-88)$ & $85(83-88)$ \\
\hline Unknown, no. (\%) & $1(2.9)$ & $0(0)$ & $1(0.7)$ \\
\hline Decreased level of consciousness, no. (\%) & $14(40)$ & $57(56)$ & $71(52)$ \\
\hline Unknown & $0(0)$ & $1(1.0)$ & $1(0.7)$ \\
\hline Dyspnea, no. (\%) & $25(71)$ & $19(19)$ & $44(32)$ \\
\hline Unknown & $0(0)$ & $0(0)$ & $0(0)$ \\
\hline Edema, no. (\%) & $13(37)$ & $48(47)$ & $61(45)$ \\
\hline Unknown & $0(0)$ & $6(5.9)$ & $6(4.4)$ \\
\hline \multicolumn{4}{|l|}{ Oral intake, no. (\%) } \\
\hline Normal & $8(23)$ & $10(9.8)$ & $43(31)$ \\
\hline Reduced & $19(54)$ & $55(54)$ & $74(54)$ \\
\hline Impossible & $7(20)$ & $36(35)$ & $18(13)$ \\
\hline Unknown & $1(2.9)$ & $1(1.0)$ & $2(1.5)$ \\
\hline \multicolumn{4}{|l|}{ ECOG performance status, no. (\%) } \\
\hline 1 & $0(0)$ & $1(1.0)$ & $1(0.7)$ \\
\hline 2 & $9(26)$ & $8(7.8)$ & $17(12)$ \\
\hline 3 & $17(49)$ & $46(45)$ & $63(46)$ \\
\hline 4 & $9(26)$ & $44(43)$ & $53(39)$ \\
\hline Unknown & $0(0)$ & $3(2.9)$ & $3(2.2)$ \\
\hline Cardiopulmonary comorbidity, no. (\%) & $11(31)$ & $4(3.9)$ & $15(11)$ \\
\hline Heart failure & $5(14)$ & $3(2.9)$ & $8(5.8)$ \\
\hline Chronic obstructive pulmonary disease & $4(11)$ & $1(1.0)$ & $5(3.6)$ \\
\hline Interstitial lung disease or radiation pneumonitis & $4(11)$ & $1(1.0)$ & $5(3.6)$ \\
\hline Severe asthma & $1(2.9)$ & $0(0)$ & $1(0.7)$ \\
\hline \multicolumn{4}{|l|}{ Primary tumor sites, no. (\%) } \\
\hline Gastrointestinal & $11(31)$ & $53(52)$ & $64(47)$ \\
\hline Lung & $14(40)$ & $23(23)$ & $37(27)$ \\
\hline Urologic & $3(8.6)$ & $14(14)$ & $17(12)$ \\
\hline Hematologic & $4(11)$ & $3(2.9)$ & $7(5.1)$ \\
\hline Head and neck & $1(2.9)$ & $4(3.9)$ & $5(3.6)$ \\
\hline Unknown & $2(5.7)$ & $2(2.0)$ & $4(2.9)$ \\
\hline Gynecologic & $1(2.9)$ & $2(2.0)$ & $3(2.2)$ \\
\hline Breast & $0(0)$ & $2(2.0)$ & $2(1.5)$ \\
\hline Central nervous system & $1(2.9)$ & $1(1.0)$ & $2(1.5)$ \\
\hline Skin (melanoma) & $0(0)$ & $1(1.0)$ & $1(0.7)$ \\
\hline
\end{tabular}


Table 2 Patient outcome according to oxygen use

\begin{tabular}{|c|c|c|c|}
\hline Oxygen saturation, median (IQR), \% & $\begin{array}{l}\text { Oxygen use } \\
(n=35)\end{array}$ & $\begin{array}{l}\text { No oxygen use } \\
(n=102)\end{array}$ & $\begin{array}{l}\text { Total } \\
(n=137)\end{array}$ \\
\hline Oxygen saturation at baseline & $85(82-87)$ & $86(83-88)$ & $85(83-88)$ \\
\hline Highest oxygen saturation during follow-up at home & $96(94-98)$ & $89(85-96)$ & $93(88-97)$ \\
\hline Lowest oxygen saturation during follow-up at home & $83(80-86)$ & $84(80-87)$ & $84(80-87)$ \\
\hline $\begin{array}{l}\text { Time from the development of low oxygen saturation to the initiation } \\
\text { of oxygen therapy, median (IQR), days }\end{array}$ & $0(0-4)$ & - & - \\
\hline Outcome at end of entire follow-up, no. (\%) & $\begin{array}{l}\text { Oxygen use } \\
(n=35)\end{array}$ & $\begin{array}{l}\text { No oxygen use } \\
(n=102)\end{array}$ & $\begin{array}{l}\text { Total } \\
(n=137)\end{array}$ \\
\hline Died & $33(94)^{a}$ & $96(94)^{a}$ & $129(94)$ \\
\hline Admitted to a hospital including PCU & $2(5.7)$ & $5(4.9)$ & $7(5.1)$ \\
\hline Switched to outpatient follow-up & $0(0)$ & $1(1.0)$ & $1(0.7)$ \\
\hline Outcome at end of follow-up at home, no. (\%) & $\begin{array}{l}\text { Oxygen use } \\
(n=35)\end{array}$ & $\begin{array}{l}\text { No oxygen use } \\
(n=102)\end{array}$ & $\begin{array}{l}\text { Total } \\
(n=137)\end{array}$ \\
\hline Died at home & $23(66)^{b}$ & $77(75)^{b}$ & $100(73)$ \\
\hline Admitted to a hospital including PCU & $12(34)$ & $23(23)$ & $35(26)$ \\
\hline Died during emergency transport & $0(0)$ & $1(1.0)$ & $1(0.7)$ \\
\hline Switched to outpatient follow-up & $0(0)$ & $1(1.0)$ & $1(0.7)$ \\
\hline Survival, median (IQR), days & $\begin{array}{l}\text { Oxygen use } \\
(n=33)\end{array}$ & $\begin{array}{l}\text { No oxygen use } \\
(n=96)\end{array}$ & $\begin{array}{l}\text { Total } \\
(n=129)\end{array}$ \\
\hline \multirow[t]{2}{*}{ Overall survival } & $15(6-35)$ & $5(1-19)$ & $7(2-23)$ \\
\hline & $(n=35)$ & $(n=102)$ & $(n=137)$ \\
\hline Survival at home & $19(7-46)$ & $6(2-29)$ & $10(2-31)$ \\
\hline
\end{tabular}

$I Q R$ Interquartile range, $P C U$ Palliative care unit

${ }^{a} p=1.0$ for the difference in the proportion of patients who died (Fisher's exact test)

${ }^{\mathrm{b}} p=0.28$ for the difference in the proportion of patients who died at home (Fisher's exact test)

low oxygen saturation reading by pulse oximetry may not necessarily be an accurate reflection of arterial hypoxemia. Falsely low readings of oxygen saturation by pulse oximetry may occur in various settings and medical conditions, such as hypoperfusion $[35,36]$. While pulse oximetry is thus limited, evaluating hypoxemia by arterial blood gas is invasive and may not be suitable in palliative care settings. Third, excessive oxygen supplementation may be harmful as was shown in a meta-analysis of randomized controlled trials, in which liberal oxygen therapy increased mortality in acutely ill adults [37].

Our findings suggest that, in patients with advanced cancer and low oxygen saturation, it may not be necessary to use oxygen for prolongation of survival, particularly in those without dyspnea. Although the exploratory nature of our study precludes definitive conclusion, we believe that the use of oxygen in patients without dyspnea cannot be recommended at present because it may interfere with daily activities, produce nasal irritation, and increase the cost of care. A randomized controlled trial or a larger prospective cohort study is needed to confirm our findings, including the possible prolongation of survival by oxygen use in patients with dyspnea. In such patients, the decision whether to use oxygen or not should be individualized, taking into consideration the uncertainty of its effect on dyspnea and patients' and caregivers' perceptions of oxygen therapy. Of note, fan therapy may be an effective and less expensive alternative for the relief of dyspnea in patients with advanced cancer [38-40].

This study has several limitations. First, we cannot entirely rule out the possibility of unmeasured or unknown confounders that may influence the results because this was an observational study. For example, clinical prediction of survival has been found to be a prognostic factor for survival in patients with advanced cancer, although it tended to overestimate the length of actual survival $[25,26,41,42]$. It may not change our conclusions, however, because the bias it could have introduced would overestimate the effect of oxygen use on survival, provided that physicians were more likely to use oxygen in patients with longer life expectancy. Respiratory rate was another potential confounder that we could not adjust for because of a large amount of missing data. A few studies have found that respiratory rate was a prognostic factor for survival $[27,28]$. Other factors that we could not adjust for were etiologies of dyspnea/ 


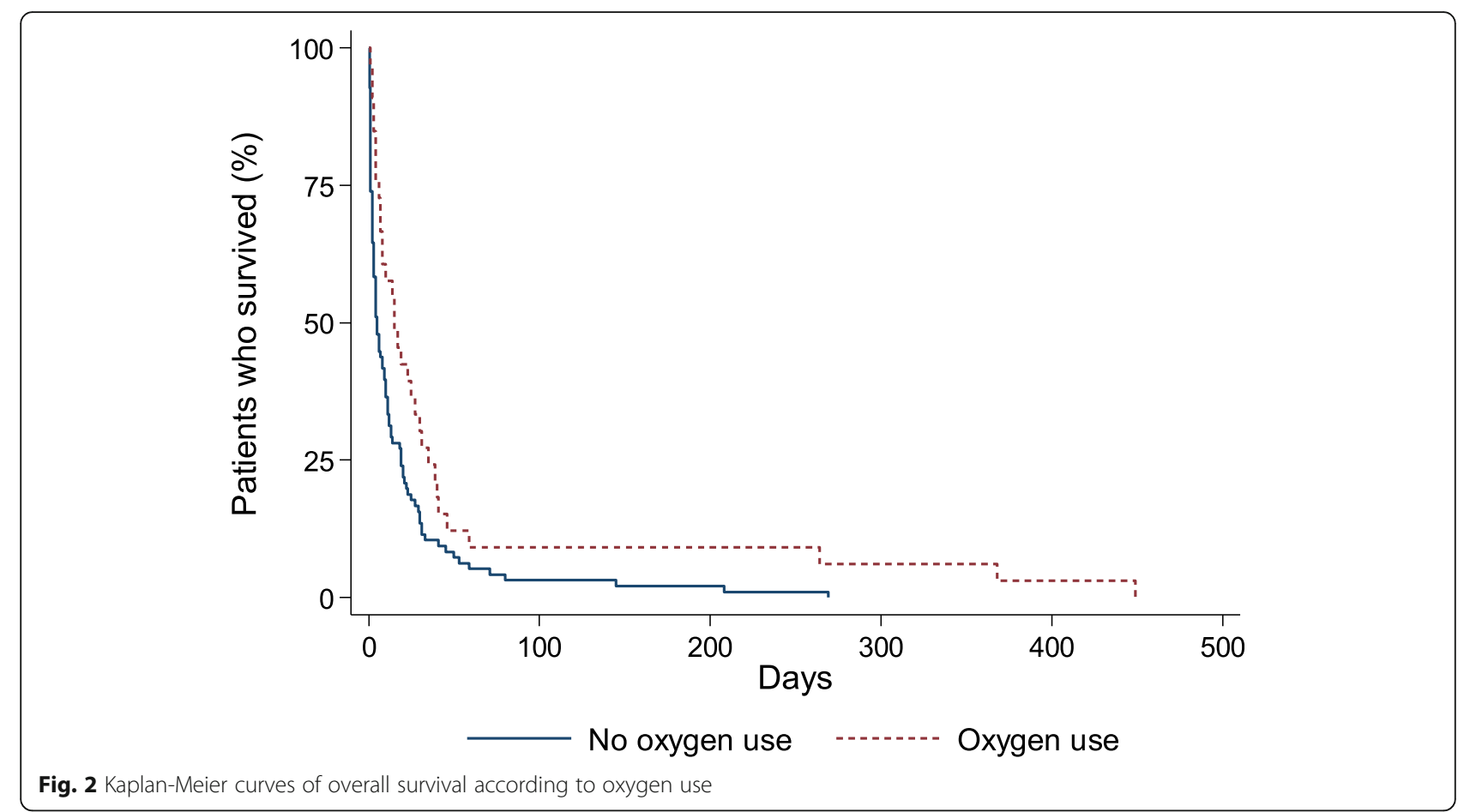

low oxygen saturation (parenchymal pulmonary involvement other than lung cancer as the primary tumor, including pneumonia and lymphangitis carcinomatosa); the acuity and persistence of desaturation; and concurrent pharmacological treatment of dyspnea other than supplemental oxygen, as well as palliative sedation. Etiologies of dyspnea/ low oxygen saturation could not be determined in most cases because of the limited diagnostic resources in home care. Although we ascertained the highest and lowest readings of oxygen saturation during the follow-up at home (Table 2), we could not assess the acuity and persistence of desaturation completely. As for concurrent use of medications for dyspnea, we did not consider them as potential confounders because previous literature suggested that opioid use at the end of life $[43,44]$ or palliative sedation [45-47] were not associated with patient survival. Although we adjusted for major prognostic factors for survival in patients with advanced cancer, the relatively small sample size of

Table 3 Univariate analysis of oxygen use and potential confounders for survival

\begin{tabular}{|c|c|c|c|c|}
\hline & \multicolumn{2}{|l|}{ Death } & \multicolumn{2}{|l|}{ Death at home } \\
\hline & Unadjusted HR (95\% Cl) & $p$-value & Unadjusted HR (95\% Cl) & $p$-value \\
\hline Oxygen use & $0.59(0.39-0.88)$ & 0.011 & $0.58(0.36-0.92)$ & 0.021 \\
\hline Age & $0.99(0.97-1.00)$ & 0.16 & $0.99(0.98-1.01)$ & 0.50 \\
\hline Sex, male & $1.33(0.93-1.91)$ & 0.12 & $1.25(0.83-1.89)$ & 0.28 \\
\hline Systolic blood pressure & $0.99(0.98-1.00)$ & 0.008 & $0.98(0.97-0.99)$ & 0.002 \\
\hline Heart rate & $1.00(0.99-1.01)$ & 0.94 & $1.01(1.00-1.02)$ & 0.24 \\
\hline Oxygen saturation & $1.02(0.98-1.06)$ & 0.28 & $1.02(0.98-1.07)$ & 0.27 \\
\hline Decreased level of consciousness & $2.26(1.57-3.24)$ & $<0.001$ & $2.81(1.86-4.24)$ & $<0.001$ \\
\hline Dyspnea & $0.83(0.57-1.20)$ & 0.32 & $0.98(0.64-1.49)$ & 0.92 \\
\hline Edema & $1.09(0.76-1.55)$ & 0.64 & $1.14(0.76-1.71)$ & 0.51 \\
\hline Oral intake & $0.48(0.36-0.62)$ & $<0.001$ & $0.31(0.22-0.43)$ & $<0.001$ \\
\hline Performance status & $1.68(1.29-2.18)$ & $<0.001$ & $2.14(1.59-2.87)$ & $<0.001$ \\
\hline Cardiopulmonary comorbidity & $0.44(0.25-0.80)$ & 0.006 & $0.46(0.23-0.91)$ & 0.026 \\
\hline Lung cancer as primary tumor & $0.76(0.51-1.14)$ & 0.18 & $0.73(0.45-1.17)$ & 0.19 \\
\hline
\end{tabular}


Table 4 Multivariate analysis of oxygen use and potential confounders for survival

\begin{tabular}{|c|c|c|c|c|}
\hline & \multicolumn{2}{|l|}{ Death } & \multicolumn{2}{|l|}{ Death at home } \\
\hline & Adjusted HR (95\% Cl) & $\overline{p \text {-value }}$ & Adjusted HR (95\% Cl) & $p$-value \\
\hline Oxygen use & $0.68(0.39-1.17)$ & 0.16 & $0.70(0.38-1.27)$ & 0.24 \\
\hline Systolic blood pressure & $1.00(0.99-1.01)$ & 0.41 & $1.00(0.99-1.01)$ & 0.75 \\
\hline Decreased level of consciousness & $1.90(1.21-2.99)$ & 0.005 & $2.01(1.22-3.33)$ & 0.006 \\
\hline Dyspnea & $1.22(0.75-1.99)$ & 0.43 & $1.25(0.75-2.11)$ & 0.39 \\
\hline Oral intake & $0.55(0.40-0.76)$ & $<0.001$ & $0.37(0.24-0.55)$ & $<0.001$ \\
\hline Performance status & $0.92(0.64-1.32)$ & 0.65 & $1.09(0.74-1.61)$ & 0.66 \\
\hline Cardiopulmonary comorbidity & $0.90(0.47-1.74)$ & 0.75 & $1.04(0.48-2.26)$ & 0.92 \\
\hline
\end{tabular}

Cl Confidence interval, $H R$ Hazard ratio

our study did not allow us to assess potential confounders comprehensively. Second, this study could be underpowered to detect the statistical significance for survival between the two groups because its sample size was relatively small. Based on this preliminary study, we calculated that 587 patients would be needed to detect a multivariate-adjusted hazard ratio of 0.68 for death with $90 \%$ power, a two-sided alpha level of 0.05 and $94 \%$ event rate of death. To meet the sample size requirement, we plan to continue recruiting participants to our study, the results of which will be reported in their entirety in the future. Third, we may not have identified all patients with low oxygen saturation, particularly in the last few days of their lives. The prevalence of low oxygen saturation in this study was lower than those in previous studies [1-3]. Those investigators measured oxygen saturation more frequently (e.g., twice daily) than we did in this study (only on the day we visited the patient's home, typically once or twice plus as needed in a week). Fourth, the retrospective design of this study could have led to some misclassifications of potential confounders, particularly for oral intake and performance status, which we determined according to the description in the patient's medical record. Fifth, although patients were checked for their symptoms including dyspnea and delirium on every visit, recording of these symptoms depended on the subjective report of the patient (or their family if the patient could not convey their symptoms) because no validated assessment tool was used for screening dyspnea or delirium. This could have led to under (or over)-estimation of these symptoms especially in patients who had difficulty in reporting their symptoms. Sixth, in terms of supplemental oxygen, intermittent use was allowed at the patient's request. Patients may have applied intermittent use of oxygen frequently due to its inconvenience at the end of life. We do not have data regarding what proportion of patients used supplemental oxygen constantly or intermittently, which may have influenced the outcomes. Seventh, the pathophysiological basis of the effect modification of oxygen by dyspnea is unclear. Dyspnea was prespecified as a potential effect modifier because, if there was an effect modification by dyspnea, we presumed it to be clinically useful when considering the use of supplemental oxygen. Eighth, we could not measure dyspnea and quality of life as outcomes in our study. Although they are important at the end of life, evaluating these outcomes was not the main objective of our study. In addition, the effect of oxygen on dyspnea in patients with advanced cancer and low oxygen saturation has already been evaluated in randomized controlled trials [12-15]. Finally, the generalizability of the findings may be limited given that this study included patients with advanced cancer in home care with relatively short survival. The results of this study may not apply to patients with longer life expectancy.

\section{Conclusions}

Oxygen use was not significantly associated with increased survival in patients with advanced cancer and low oxygen saturation, after adjusting for known prognostic factors and cardiopulmonary comorbidity. It may not be necessary to use oxygen for survival-prolongation in such patients, particularly in those without dyspnea.

Table 5 Effect modification of oxygen use by dyspnea

\begin{tabular}{|c|c|c|c|c|c|c|}
\hline & \multicolumn{3}{|l|}{ Death } & \multicolumn{3}{|c|}{ Death at home } \\
\hline & No. (\%) & Adjusted HR $(95 \% \mathrm{Cl})$ & $p$-value & No. (\%) & Adjusted HR $(95 \% \mathrm{Cl})$ & $p$-value \\
\hline Dyspnea present $(n=44)$ & $42(95)$ & $0.35(0.13-0.89)$ & 0.027 & $32(73)$ & $0.33(0.11-0.96)$ & 0.041 \\
\hline Dyspnea absent $(n=93)$ & $87(94)$ & $1.03(0.49-2.17)$ & 0.94 & $68(73)$ & $0.84(0.36-1.96)$ & 0.68 \\
\hline
\end{tabular}

$\mathrm{Cl}$ Confidence interval, HR Hazard ratio 


\section{Abbreviations}

Cl: Confidence interval; ECOG: Eastern Cooperative Oncology Group; HR: Hazard ratio; ICPC-2: International Classification of Primary Care, second edition; IQR: Interquartile range; MICE: Multiple imputation by chained equations; PCU: Palliative care unit; SD: Standard deviation

\section{Acknowledgments}

We thank Gillian Campbell, PhD, from Edanz Group for editing a draft of this manuscript.

\section{Authors' contributions}

$\mathrm{HI}$ conceived the study, performed the analysis and drafted the manuscript. $\mathrm{HI}, \mathrm{MF}$ and NN participated in the study design and were involved in data collection. HI, MF and NN participated in the revision of the manuscript and all approved the final manuscript.

\section{Funding}

The authors declare that they received no funding for this study.

\section{Availability of data and materials}

The datasets used and/or analyzed during the current study are available from the corresponding author on reasonable request.

\section{Ethics approval and consent to participate}

All procedures performed in studies involving human participants were in accordance with the ethical standards of the institutional and/or national research committee and with the 1964 Declaration of Helsinki and its later amendments or comparable ethical standards. This study was approved by the Ethics Committee at Musashi Kokubunji Park Clinic (Institutional Review Board study ID: 004) with a waiver of informed consent.

\section{Consent for publication}

Not applicable.

\section{Competing interests}

The authors declare that they have no competing interests.

Received: 1 August 2019 Accepted: 26 December 2019

\section{Published online: 03 January 2020}

\section{References}

1. Bruera S, Chisholm G, Dos Santos R, Crovador C, Bruera E, Hui D. Variations in vital signs in the last days of life in patients with advanced cancer. J Pain Symptom Manag. 2014;48(4):510-7.

2. Hui D, Dos Santos R, Chisholm G, Bansal S, Souza Crovador C, Bruera E. Bedside clinical signs associated with impending death in patients with advanced cancer: preliminary findings of a prospective, longitudinal cohort study. Cancer. 2015;121(6):960-7.

3. Hwang IC, Ahn HY, Park SM, Shim JY, Kim KK. Clinical changes in terminally ill cancer patients and death within $48 \mathrm{~h}$ : when should we refer patients to a separate room? Support Care Cancer. 2013;21(3):835-40.

4. Sato K, Miyashita M, Morita T, Tsuneto S, Shima Y. End-of-life medical treatments in the last two weeks of life in palliative care units in Japan, 2005-2006: a Nationwide retrospective cohort survey. J Palliat Med. 2016; 19(11):1188-96.

5. Jaturapatporn D, Moran E, Obwanga C, Husain A. Patients' experience of oxygen therapy and dyspnea: a qualitative study in home palliative care. Support Care Cancer. 2010:18(6):765-70.

6. Collier A, Breaden K, Phillips JL, Agar M, Litster C, Currow DC. Caregivers' perspectives on the use of long-term oxygen therapy for the treatment of refractory breathlessness: a qualitative study. J Pain Symptom Manag. 2017:53(1):33-9

7. Quinn-Lee L, Weggel J, Moch SD. Use of oxygen at the end of life: attitudes, beliefs, and practices in Wisconsin. WMJ. 2018;117(1):7-12.

8. Bruera E, Sweeney C, Willey J, Palmer JL, Strasser F, Morice RC, et al. A randomized controlled trial of supplemental oxygen versus air in cancer patients with dyspnea. Palliat Med. 2003;17(8):659-63.

9. Ahmedzai SH, Laude E, Robertson A, Troy G, Vora V. A double-blind, randomised, controlled phase II trial of Heliox28 gas mixture in lung cancer patients with dyspnoea on exertion. Br J Cancer. 2004;90(2):366-71.
10. Uronis HE, Currow DC, McCrory DC, Samsa GP, Abernethy AP. Oxygen for relief of dyspnoea in mildly- or non-hypoxaemic patients with cancer: a systematic review and meta-analysis. Br J Cancer. 2008;98(2):294-9.

11. Abernethy AP, McDonald CF, Frith PA, Clark K, Herndon JE 2nd, Marcello J et al. Effect of palliative oxygen versus room air in relief of breathlessness in patients with refractory dyspnoea: a double-blind, randomised controlled trial. Lancet. 2010;376(9743):784-93.

12. Bruera $E$, Schoeller T, MacEachern T. Symptomatic benefit of supplemental oxygen in hypoxemic patients with terminal cancer: the use of the $\mathrm{N}$ of 1 randomized controlled trial. J Pain Symptom Manag. 1992;7(6):365-8

13. Bruera E, de Stoutz N, Velasco-Leiva A, Schoeller T, Hanson J. Effects of oxygen on dyspnoea in hypoxaemic terminal-cancer patients. Lancet. 1993; 342(8862):13-4.

14. Booth S, Kelly MJ, Cox NP, Adams L, Guz A. Does oxygen help dyspnea in patients with cancer? Am J Respir Crit Care Med. 1996;153(5):1515-8.

15. Philip J, Gold M, Milner A, Di lulio J, Miller B, Spruyt O. A randomized, double-blind, crossover trial of the effect of oxygen on dyspnea in patients with advanced cancer. J Pain Symptom Manag. 2006:32(6):541-50.

16. Ramchandran K, Shega JW, Von Roenn J, Schumacher M, Szmuilowicz E, Rademaker A, et al. A predictive model to identify hospitalized cancer patients at risk for 30-day mortality based on admission criteria via the electronic medical record. Cancer. 2013;119(11):2074-80.

17. Sato K, Yokoi H, Tsuneto S. Shock Index and Decreased Level of Consciousness as Terminal Cancer Patients' Survival Time Predictors: A Retrospective Cohort Study. J Pain Symptom Manag. 2016;51(2):220-31 e2.

18. Martins SJ, Ho N, Cavamura SO, Harada CM, Yamamoto CA, Takagaki TY. Lung cancer symptoms and pulse oximetry in the prognostic assessment of patients with lung cancer. BMC Cancer. 2005;5:72.

19. Nocturnal Oxygen Therapy Trial Group. Continuous or nocturnal oxygen therapy in hypoxemic chronic obstructive lung disease: a clinical trial. Ann Intern Med. 1980:93(3):391-8.

20. Report of the Medical Research Council Working Party. Long term domiciliary oxygen therapy in chronic hypoxic cor pulmonale complicating chronic bronchitis and emphysema. Lancet. 1981;1(8222):681-6.

21. Long-Term Oxygen Treatment Trial Research Group, Albert RK, Au DH, Blackford AL, Casaburi R, Cooper JA Jr, Criner GJ, et al. A randomized trial of long-term oxygen for COPD with moderate desaturation. N Engl J Med. 2016;375(17):1617-27.

22. Elsayem A, Mori M, Parsons HA, Munsell MF, Hui D, Delgado-Guay MO, et al. Predictors of inpatient mortality in an acute palliative care unit at a comprehensive cancer center. Support Care Cancer. 2010;18(1):67-76.

23. Mercadante S, Valle A, Porzio G, Aielli F, Adile C. Casuccio a; home care-Italy group. Prognostic factors of survival in patients with advanced cancer admitted to home care. J Pain Symptom Manag. 2013;45(1):56-62.

24. Morita T, Tsunoda J, Inoue S, Chihara S. The palliative prognostic index: a scoring system for survival prediction of terminally ill cancer patients. Support Care Cancer. 1999; 7(3):128-33.

25. Viganò A, Dorgan M, Buckingham J, Bruera E, Suarez-Almazor ME. Survival prediction in terminal cancer patients: a systematic review of the medical literature. Palliat Med. 2000;14(5):363-74.

26. Maltoni M, Caraceni A, Brunelli C, Broeckaert B, Christakis N, Eychmueller S, et al. Steering Committee of the European Association for palliative care. Prognostic factors in advanced cancer patients: evidence-based clinical recommendations--a study by the steering Committee of the European Association for palliative care. J Clin Oncol. 2005;23(25):6240-8.

27. de Miguel SC, Elustondo SG, Estirado A, Sánchez FV, de la Rasilla Cooper CG Romero AL, et al. Palliative performance status, heart rate and respiratory rate as predictive factors of survival time in terminally ill cancer patients. J Pain Symptom Manag. 2006;31(6):485-92.

28. Chiang JK, Lai NS, Wang MH, Chen SC, Kao YH. A proposed prognostic 7day survival formula for patients with terminal cancer. BMC Public Health. 2009;9:365.

29. Fukushi M, Ishibashi Y, Nago N. Final diagnoses and probability of new reason-for-encounter at an urban clinic in Japan: a 4-year observational study. Medicine (Baltimore). 2017:96(22):e6999.

30. The Classification Committee of WONCA. ICPC-2, International Classification of Primary Care. 2nd ed. Oxford: Oxford University Press; 1998.

31. Oken MM, Creech RH, Tormey DC, Horton J, Davis TE, McFadden ET, et al. Toxicity and response criteria of the eastern cooperative oncology group. Am J Clin Oncol. 1982;5(6):649-55. 
32. Schildmann J, Baumann A, Cakar M, Salloch S, Vollmann J. Decisions about limiting treatment in Cancer patients: a systematic review and clinical ethical analysis of reported variables. J Palliat Med. 2015;18(10):884-92.

33. Campos-Calderón C, Montoya-Juárez R, Hueso-Montoro C, Hernández-López E, Ojeda-Virto F, García-Caro MP. Interventions and decision-making at the end of life: the effect of establishing the terminal illness situation. BMC Palliat Care. 2016;15(1):91.

34. Bruera E, Hui D, Dalal S, Torres-Vigil I, Trumble J, Roosth J, et al. Parenteral hydration in patients with advanced cancer: a multicenter, double-blind, placebo-controlled randomized trial. J Clin Oncol. 2013;31(1):111-8.

35. Van de Louw A, Cracco C, Cerf C, Harf A, Duvaldestin P, Lemaire F, et al. Accuracy of pulse oximetry in the intensive care unit. Intensive Care Med. 2001;27(10):1606-13

36. Chan ED, Chan MM, Chan MM. Pulse oximetry: understanding its basic principles facilitates appreciation of its limitations. Respir Med. 2013; 107(6):789-99.

37. Chu DK, Kim LH, Young PJ, Zamiri N, Almenawer SA, Jaeschke R, et al. Mortality and morbidity in acutely ill adults treated with liberal versus conservative oxygen therapy (IOTA): a systematic review and meta-analysis. Lancet. 2018;391(10131):1693-705.

38. Galbraith S, Fagan P, Perkins P, Lynch A, Booth S. Does the use of a handheld fan improve chronic dyspnea? A randomized, controlled, crossover trial. J Pain Symptom Manag. 2010;39(5):831-8.

39. Wong SL, Leong SM, Chan CM, Kan SP, Cheng HW. The effect of using an electric fan on dyspnea in Chinese patients with terminal Cancer. Am J Hosp Palliat Care. 2017:34(1):42-6.

40. Kako J, Morita T, Yamaguchi T, Kobayashi M, Sekimoto A, Kinoshita H, et al. Fan therapy is effective in relieving dyspnea in patients with terminally ill Cancer: a parallel-arm, randomized controlled trial. J Pain Symptom Manag. 2018;56(4):493-500.

41. Pirovano M, Maltoni M, Nanni O, Marinari M, Indelli M, Zaninetta G, et al. A new palliative prognostic score: a first step for the staging of terminally ill cancer patients. Italian multicenter and study group on palliative care. J Pain Symptom Manag. 1999;17(4):231-9.

42. Glare P, Virik K, Jones M, Hudson M, Eychmuller S, Simes J, et al. A systematic review of physicians' survival predictions in terminally ill cancer patients. BMJ. 2003;327(7408):195-8.

43. López-Saca JM, Guzmán JL, Centeno C. A systematic review of the influence of opioids on advanced cancer patient survival. Curr Opin Support Palliat Care. 2013;7(4):424-30

44. Boland JW, Ziegler L, Boland EG, McDermid K, Bennett MI. Is regular systemic opioid analgesia associated with shorter survival in adult patients with cancer? A systematic literature review. Pain. 2015;156(11):2152-63.

45. Maltoni M, Scarpi E, Rosati M, Derni S, Fabbri L, Martini F, et al. Palliative sedation in end-of-life care and survival: a systematic review. J Clin Oncol. 2012:30(12):1378-83.

46. Beller EM, van Driel ML, McGregor L, Truong S, Mitchell G. Palliative pharmacological sedation for terminally ill adults. Cochrane Database Syst Rev. 2015;1:CD010206.

47. Maeda I, Morita T, Yamaguchi T, Inoue S, Ikenaga M, Matsumoto Y, et al. Effect of continuous deep sedation on survival in patients with advanced cancer (J-Proval): a propensity score-weighted analysis of a prospective cohort study. Lancet Oncol. 2016;17(1):115-22.

\section{Publisher's Note}

Springer Nature remains neutral with regard to jurisdictional claims in published maps and institutional affiliations.

\section{Ready to submit your research? Choose BMC and benefit from:}

- fast, convenient online submission

- thorough peer review by experienced researchers in your field

- rapid publication on acceptance

- support for research data, including large and complex data types

- gold Open Access which fosters wider collaboration and increased citations

- maximum visibility for your research: over $100 \mathrm{M}$ website views per year

At BMC, research is always in progress.

Learn more biomedcentral.com/submissions 